Homepage: http://www.ojs.ufpi.br/index.php/jibi

\author{
Jurandyr Reis Neto ${ }^{1}$ \\ Geuan Pereira Reis ${ }^{1}$ \\ Vivian Costa Vasconcelos ${ }^{1}$ \\ Iru Menezes Guimarães ${ }^{2}$ \\ Elton Lima Santos ${ }^{1}$
}

1. Universidade Federal de Alagoas

${ }^{2}$.Companhia de Desenvolvimento dos Vales do São Francisco

K E Y W O R D S

Adaptation; diet composition; intestine.

P A L A V R A S - C H A V E

Adaptação; composição da dieta; intestino.

AUTOR CORRESPONDENTE:

Jurandyr Reis Neto

<jurandyrengpesca@outlook.com.>

Laboratório de Aquicultura, Centro de Ciências Agrárias, UFAL, BR - 104, CEP 57100-000. Rio Largo - AL - Brasil

Submetido em: 26/06/2018

Aceito em: 12/11/2018
Artigo original

\section{Morfologia comparativa do trato digestório de tilápias do Nilo (Oreochromis niloticus) cultivadas em sistema semi-intensivo vs da pesca artesanal}

Comparative morphology of the digestive tract of Nile tilapia

(Oreochromis niloticus) farmed in a semi-intensive system vs. artisanal fishing

\begin{abstract}
A B S T R A C T
The objective of this study was to evaluate and compare the morphology of the digestive tract of Nile tilapia (Oreochromis niloticus), from semi - intensive farming and artisanal fishing in the São Francisco river. Six specimens were used (four by farming and two for artisanal fisheries). $4 \mathrm{ml}$ of $4 \%$ formalin was injected into the peritoneal cavity of the specimens, and then immersed in formalin solution for $48 \mathrm{~h}$. Biometrics of all specimens were made, measuring the total length (CT), standard length (CP) and weight. A tape measure $(\mathrm{cm})$, caliper rule and precision balance were used. The gills were removed using surgical scissors. A latero-ventral incision was made to visualize the arrangement of the organs in the peritoneal cavity. The organs were removed and the digestive tract was carefully separated to analyze its morphology and make photographic records. The intestinal coefficient (IC) was obtained based on the length of the intestine related to the body length $(\mathrm{Ci} / \mathrm{Cp})$. The farmed Tilapia showed $\mathrm{CT}$ between $16-22.5 \mathrm{~cm}$ and $\mathrm{CP} 12-$ $19.3 \mathrm{~cm}$ and weight between 70-210g. Tilapias from extractive fishing showed CT between 19$20.2 \mathrm{~cm}$, CP between $16.6-17.6 \mathrm{~cm}$ and weight between $177.7-178.3 \mathrm{~g}$. The mouth, in all copies, is provided with denticles. The gill arch shows long filaments and evenly distributed traces, ratifying its omnivorous habit. The digestive tract comprises the anterior, middle and posterior regions. The stomach is sacculating and partially stores the food. All specimens exhibited high CI $(3.02-9.32 \mathrm{~cm})$, which compensates for the lack or reduction of pyloric cecum, but the culture specimens expressed higher IC and absorption area, indicating a possible influence of diet on the conformation of the tract. The robustness of the treatment in fish species may be related to natural selection and / or periods of abundance and food shortage. O. niloticus, because they are omnivorous, have an easy way of adapting the morphology of the digestive tract based on diet. This study provides strong evidence of the influence of inert and natural food on the gastrointestinal morphological variation of this species.
\end{abstract}

R E S U M O

Objetivou-se, nesse estudo, avaliar e comparar a morfologia do trato digestório de tilápias do Nilo (Oreochromis niloticus), oriundas de cultivo semi-intensivo e da pesca artesanal no rio São Francisco. Utilizou-se seis exemplares (quatro de cultivo e dois da pesca artesanal). Injetou-se $4 \mathrm{ml}$ de formol $4 \%$ na cavidade peritoneal dos espécimes, posteriormente, mantidos imersos em solução formol por $48 \mathrm{~h}$. Realizou-se biometrias de todos exemplares, mensurando-se o comprimento total (CT), comprimento padrão $(\mathrm{CP})$ e o peso. Utilizou-se fita métrica $(\mathrm{cm})$, paquímetro e balança de precisão. As brânquias foram removidas utilizando-se tesoura cirúrgica. Fez-se uma incisão latero-ventral para visualizar a disposição dos órgãos na cavidade peritoneal. Retirou-se os órgãos e separou-se cuidadosamente o trato digestório para analisar sua morfologia e fazer registros fotográficos. Obteve-se o coeficiente intestinal (CI) com base no comprimento do intestino relacionado ao comprimento corpóreo $(\mathrm{Ci} / \mathrm{Cp})$. As tilápias de cultivo exibiram CT entre $16-22,5 \mathrm{~cm}$ e CP $12-19,3 \mathrm{~cm}$ e peso entre $70-210 \mathrm{~g}$. As tilápias da pesca extrativa apresentaram CT entre 19-20,2cm, CP entre 16,6-17,6cm e peso entre 177,7-178,3g. A boca, em todos exemplares, é provida de dentículos. O arco branquial exibe longos filamentos e rastros distribuídos uniformemente, ratificando seu hábito onívoro. O tubo digestivo compreende as regiões anterior, média e posterior. O estômago é sacular e armazena parcialmente o alimento. Todos exemplares exibiram alto CI (3,02-9,32cm), que compensa a falta ou redução de cecos pilóricos, mas os espécimes de cultivo expressaram maior CI e área de absorção, indicando possível influência da dieta na conformação do trato. A robustez do trato nas espécies da pesca pode estar relacionada a seleção natural e/ou períodos de abundância e escassez alimentar. $O$. niloticus, por ser onívora, têm facilidade em adaptar a morfologia do trato digestivo com base na dieta. Este estudo fornece fortes indícios da influência do alimento inerte e natural na variação morfológica gastrointestinal desta espécie. 


\section{INTRODUÇÃO}

Os peixes teleósteos exibem uma grande diversidade de tamanhos, cores, formas e especializações. Tais características permitem a colonização de distintos ambientes e exploração de diferentes recursos alimentares, desse modo possibilitando a coexistência de várias espécies num mesmo habitat com diferentes hábitos alimentares.

Mudanças ambientais, como aumento da poluição e assoreamento provocados por ações antropogênicas nos meios aquáticos, vêm provocando uma série de modificações corporais nos organismos aquáticos, visto que esses necessitam adaptar-se as condições, muitas vezes, prejudiciais à sua saúde.

A piscicultura intensiva vem crescendo no Brasil de forma acelerada comparada a outras atividades agropecuárias (BANDEIRA; NASCIMENTO, 2017). No entanto, esse rápido crescimento traz como consequência a utilização cada vez mais frequente de espécies exóticas com grande potencial produtivo, em detrimento da utilização de espécies nativas pouco produtivas, mas de grande importância para o ecossistema natural.

Apesar do aumento da piscicultura, a pesca extrativa, principalmente na forma artesanal, ainda é muito representativa no mundo, pois, de acordo com a Organização das Nações Unidas para Agricultura e Alimentação (FAO, 2018), foram produzidos 171 milhões de toneladas de pescado em 2016 (91 milhões provenientes da pesca e 80 milhões da aquicultura). Sendo a pesca extrativa ainda responsável por cerca de 54\% do total de pescado produzido no mundo.

As tilápias compreendem o grupo de peixes mais cultivados e comercializados no Brasil, sendo isto devido à sua rusticidade e rápido crescimento, seja em ambientes artificiais de cultivos ou em ambientes naturais, como rios e lagos (SANTOS et al., 2009a). Seu hábito alimentar onívoro possibilita as espécies desse grupo explorarem eficientemente uma variedade de organismos animais e vegetais sem alterar negativamente seu desempenho. Adapta-se também a criações em grande escala, ou pequenas criações, constituindo uma espécie de muita importância social e econômica no Brasil (SANTOS et al., 2009b).

A morfofisiologia do trato digestório é importante para que os peixes consigam extrair o máximo de nutrientes de determinado alimento e essa característica irá definir sua preferência alimentar e provocará posteriores adaptações anatômicas.

Drewe e outros (2004) destacam que a caracterização e as diferenças relacionadas aos mecanismos de ação do trato digestório dos peixes são instrumentos básicos para o bom entendimento das suas funções e está conectada ao tipo da dieta, ao habitat e ao desenvolvimento ontogenético do indivíduo.

A mudança quantiqualitativa no componente principal na dieta e a variação do habitat podem resultar numa série de adaptações e/ou modificações do trato digestório, numa mesma espécie ou grupo de espécies, para explorar de forma eficaz o alimento. O sistema de criação e habitat dos peixes podem também interferir na morfologia do corpo e dos órgãos dos animais (BECKER et al., 2010).

Desse modo, objetiva-se no presente estudo avaliar e comparar a morfologia do trato digestório de tilápias do Nilo (Oreochromis niloticus) cultivadas em sistema semiintensivo e oriundas da pesca artesanal extrativa no rio São Francisco.

\section{MATERIAIS E MÉTODOS}

Em função do baixo quantitativo de exemplares observados, este estudo pode ser enquadrado como pesquisa exploratória. Foram utilizados seis exemplares de tilápia do Nilo (O. niloticus), sendo quatro oriundos de ambiente de cultivo semi-intensivo, do Centro Integrado de Recursos Pesqueiros e Aquicultura em Betume - SE e dois oriundos da pesca artesanal extrativa (ambiente natural) (figura 01), capturados com redes de emalhar no rio São Francisco e adquiridos logo após a retirada da água, na feira livre, situada na cidade de Penedo, Alagoas.

Para avaliação comparativa do trato gastrintestinal, foi injetado $4 \mathrm{ml}$ de formol a $4 \%$ na cavidade peritoneal de cada exemplar. Posteriormente, as amostras de peixes foram mantidas imersas em formol $4 \%$, durante $48 \mathrm{~h}$, para conservação dos tecidos e órgãos.

Os peixes, provenientes de cultivo semi-intensivo, eram mantidos em viveiros escavados com elevada taxa de renovação de água, sendo alimentados com rações fareladas (32\%PB), nas fases iniciais, e ração comercial extrusada (28\% PB), nas fases de terminação. Os viveiros em que os animais foram cultivados, passaram por manejos de adubação, calagem e biometria bimestral.

Foram realizadas biometrias de todos exemplares, mensurando-se o comprimento total (CT), comprimento padrão $(\mathrm{CP})$ e o peso. Utilizou-se fita métrica em centímetro, paquímetro e balança de precisão BS 3000A (erro $=0,1 \mathrm{~g}$ ).

Após a biometria, as brânquias de cada espécime foram retiradas com uso de tesoura cirúrgica, cortando-se a base dos arcos branquiais. Posteriormente, fez-se uma incisão latero-ventral no sentido crânio-caudal para visualizar a disposição dos órgãos na cavidade peritoneal. Em seguida, retirou-se os órgãos e separou-se cuidadosamente o trato digestório com uso de pinças e vidro relógio, colocando-o em papel de fundo branco para melhor visualização de suas características e segmentos e, posteriormente, fez-se registros fotográficos com câmera digital portátil de 10 megapixels (Samsung ${ }^{\circledR}$ ).

Foram realizadas avaliações comparativas da morfologia do trato gastrintestinal de $O$. niloticus do ambiente de cultivo semi-intensivo em relação às $O$. niloticus capturadas no ambiente natural, através da pesca artesanal. 

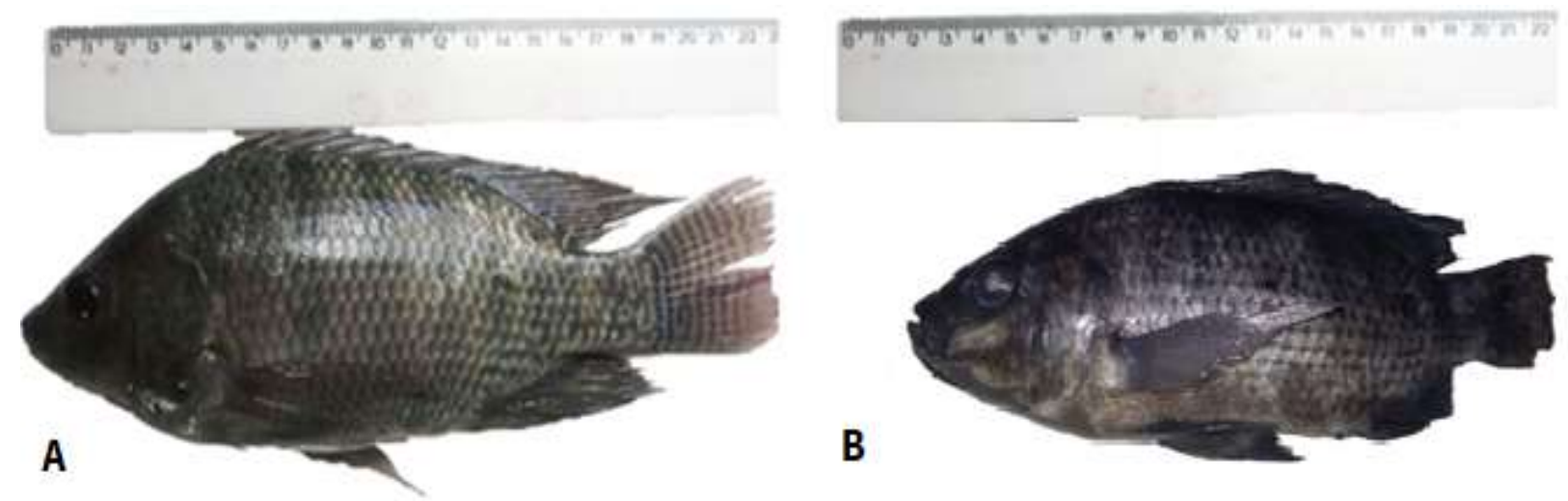

Figura 01. Exemplares de $O$. niloticus de cultivo semi-intensivo (A) e da pesca artesanal extrativa (B).

O trato digestório foi mensurado longitudinalmente e o coeficiente intestinal foi avaliado com base no comprimento do intestino em relação ao comprimento corpóreo $(\mathrm{Ci} / \mathrm{Cp})$, seguindo as recomendações de Gneri e Angelescu (1951). As conclusões e resultados foram obtidos a partir das observações de forma descritiva.

O presente estudo está de acordo com os princípios éticos de pesquisa com animais e foi aprovado pelo Comitê de Ética no Uso de Animais da Universidade Federal de Alagoas, Brasil (Protocolo no 57 /2017 - CEUA/UFAL).

\section{RESULTADOS E DISCUSSÃO}

A tilápia pode ser produzida em diferentes sistemas de cultivo e escalas, com maior ou menor dependência de insumos, principalmente ração artificial industrializada com diferentes alimentos, seja de origem animal ou vegetal. É espécie também considerada filtradora e, desse modo, pode aproveitar de forma eficaz o alimento natural disponível no meio aquático.

As tilápias estudadas, provindas do cultivo semiintensivo apresentaram comprimento total (CT) entre 16$22,5 \mathrm{~cm}$ e comprimento padrão $(\mathrm{CP})$, entre $12-19,3 \mathrm{~cm}$, com peso oscilando entre $70-210 \mathrm{~g}$. Já as tilápias da pesca artesanal extrativa exibiram CT entre 19-20,2cm e CP entre 16,6-17,6cm e oscilação do peso entre 177,7-178,3g.

De modo geral, o trato gastrintestinal da tilápia do Nilo, O. niloticus, segue um percurso complexo da passagem do alimento, que envolve múltiplas alças e espiras dispostas de forma previamente não descrita (SMITH et al., 2000). Essas características gerais foram observadas no presente estudo, tanto nos peixes provenientes da pesca extrativa como de cultivo.

O trato gastrointestinal dos exemplares é bem alongado, devido, principalmente, ao intestino médio que ocupa grande área da cavidade peritoneal, constituindo principal local de digestão química e absorção dos nutrientes (WILSON; CASTRO, 2010). O esôfago, situado após a cavidade bucal, inicia na região cefálica e interconecta boca ao estômago. Um esfíncter pilórico revela a região de transição entre estômago e intestino. $\mathrm{O}$ reto e ânus compreendem regiões posteriores ao intestino (sentido aboral).

A boca em todos exemplares é provida de estrutura calcificada e serrilhada (dentículos), apresentando um par de linhas superior e inferior, com tamanhos similares, conforme expresso na figura 02. Essas estruturas (dentículos), que são comuns a espécie, servem para capturar e triturar parcialmente o alimento ingerido, visto que não possuem dentes molariformes. $\mathrm{O}$ arco branquial apresenta estruturas bem filamentosas (filamentos branquiais) distribuídas uniformemente em todos os exemplares e os rastros branquiais são diminutos, com maior expressividade nos dois arcos iniciais de cada espécime e distribuídos de maneira uniforme, ao longo do arco branquial (figura 03).

Os rastros branquiais exibiram maior volume nas espécies da pesca artesanal extrativa, no entanto observouse um menor espaçamento entre eles. Torres e outros (2010) reporta que o arco branquial e seus filamentos constituem estruturas bem definidas e de fácil visualização nessa espécie. Essas características ratificam seu hábito onívoro.

O trato digestório, nos exemplares analisados, compreende o intestino anterior (esôfago e estômago), intestino médio (maior extensão) e intestino posterior (reto e ânus) (figura 04). Esta distribuição é comum nos teleósteos à exceção dos peixes agástricos (COSTA et al., 2015).

O estômago é curto e possui formato de "U" (tipo saco) e representa cerca de $4 \%$ do comprimento de todo trato digestivo, dividindo-se em região cárdica, fúndica e pilórica (figura 04), sendo mais perceptível nas tilápias da pesca artesanal. Este apresenta capacidade de armazenar temporariamente o alimento e iniciar sua digestão parcial. Costa e outros (2015) observaram que o estômago de Colossoma macropomum apresenta formato sacular e exibe as regiões cárdica, fúndica e pilórica bem distintas. Desse modo, indicando característica similar a espécie estudada, considerando que ambas as espécies são onívoras. Em ambos casos (cultivo e pesca extrativa), O. niloticus revelou um elevado coeficiente intestinal com $6,94-9,32 \mathrm{~cm}$ para espécimes de cultivo e 3,02-4,05cm para espécimes da pesca artesanal. Isso é importante, pois caracteriza os padrões de 
Reis Neto, J. et al.
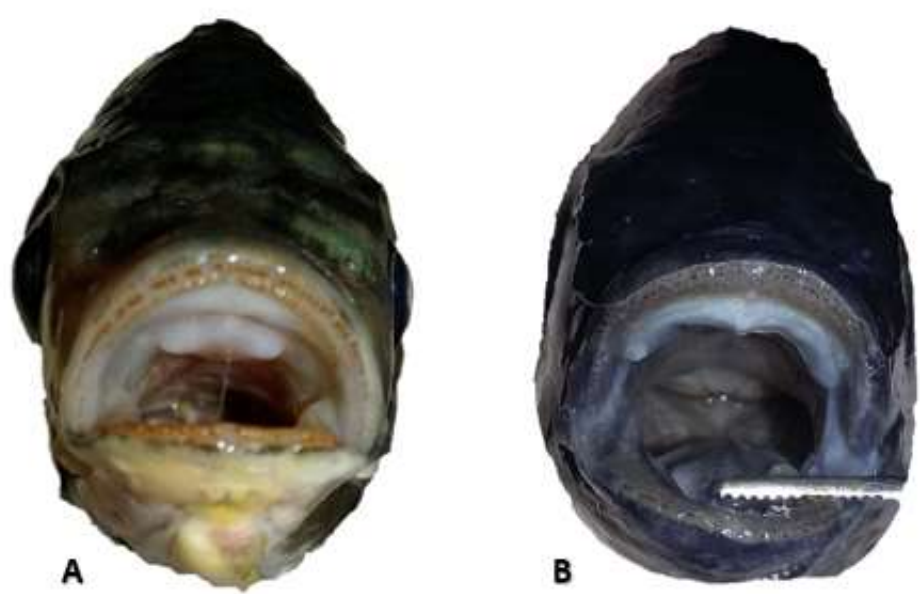

Figura 02. Boca e cavidade oral de $O$. niloticus, com destaque para os dentes. A: cultivo semi-intensivo e B: pesca artesanal.



Figura 03. Estrutura branquial de O. niloticus. (A): cultivo semi-intensivo e (B): pesca artesanal.

enrolamento das alças intestinais como enovelado, sendo também de grande valia na definição do hábito alimentar dos peixes.

Geralmente, o comprimento do intestino é proporcional ao tamanho do peixe. No entanto, os intestinos observados nas tilápias do cultivo semi-intensivo revelaram um maior comprimento (mais afilado), comparado os espécimes provenientes do ambiente natural (mais robusto), ou seja, da pesca artesanal extrativa do rio São Francisco, como podese notar na figura 05 .

Deste modo, Moraes e outros (1997) corroboram as afirmações obtidas no presente estudo, quando destacam que o comprimento do intestino está diretamente relacionado com os hábitos iliófago, herbívoro e onívoro que expressam maiores comprimentos, e é inversamente proporcional aos hábitos carnívoro e insetívoro com menores comprimentos e coeficientes intestinais.

Pode-se, então, inferir que essa característica pode indicar adaptações/modificações do trato digestório em relação ao alimento inerte e fornecimento periódico de alimento, além das características do ambiente de cultivo, possivelmente com o intuito de possibilitar uma maior absorção de nutrientes da dieta principal em $O$. niloticus de cativeiro, baseada na ração e, consequentemente, maior crescimento. Provavelmente, a qualidade nutricional, a diversidade de organismos altamente nutritivos e alternância de períodos de abundância e até uma possível escassez de alimento, no ambiente natural, favoreceram uma maior robustez e retração do trato gastrintestinal das espécies da pesca artesanal. 


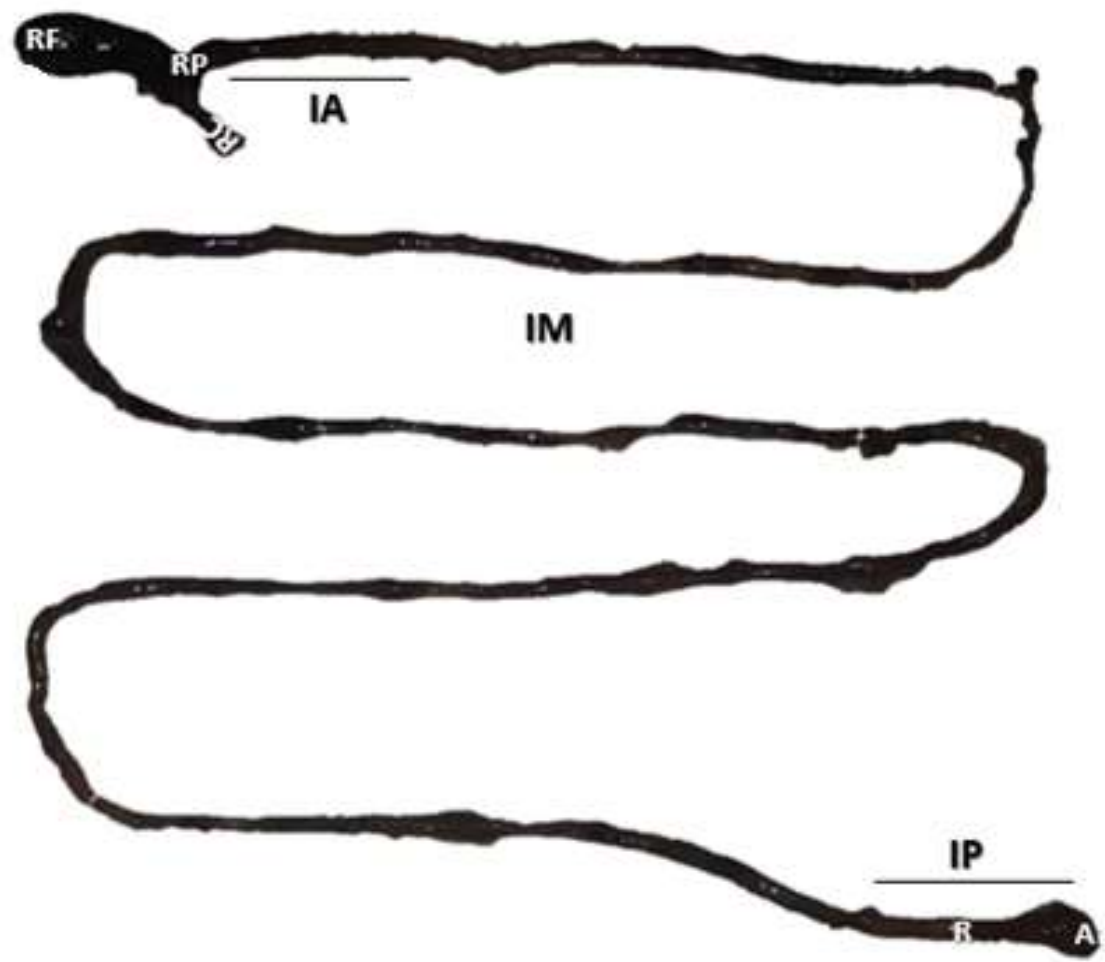

Figura 04. Trato digestório de $O$. niloticus oriunda da pesca artesanal. IA: intestino anterior, IM: intestino médio, IP: intestino posterior. Estômago: (RC: região cárdica, RF: região fúndica, RP: região pilórica), R: reto e A: ânus.

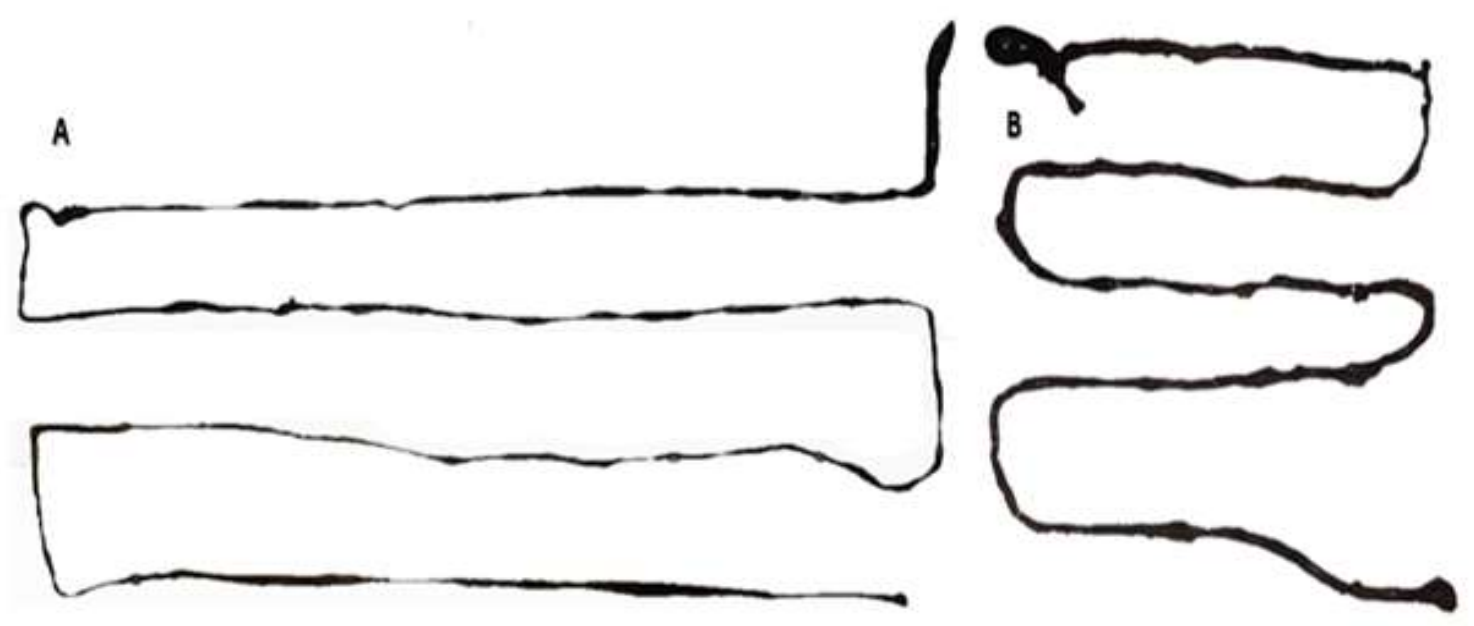

Figura 05. Comprimento comparativo do intestino de O. niloticus. A: cultivo semi-intensivo e B: pesca artesanal.

Conforme também cita Zeng e outros (2012), que relata que $O$. niloticus tende a apresentar a capacidade de retrair o tamanho e funcionalidades do trato gastrointestinal para conservar energia, quando privados de alimentos. Ainda esses autores estudaram as adaptações morfológicas ligadas ao alimento em Silurus meridionalis e relataram uma redução do trato digestivo e funções fisiológicas e bioquímicas como uma forma de adaptação a períodos de restrição alimentar.

Já Moreira e outros (2012) destacam que a ingestão do alimento natural e/ou artificial está relacionada com o desenvolvimento dos índices gastrintestinais, reforçando que estes indicadores podem sofrer alterações devido o tipo de alimentação. Costa (2017), avaliando a morfofisiologia do trato digestivo de Mugil liza de cultivo e ambiente natural, detectou diferenças em que a dieta inerte de fácil digestão possibilitou encurtamento do intestino e menor peso do estômago. Vale ressaltar que a qualidade nutricional da dieta natural de M. liza é bem inferior ao de O. niloticus.

Alguns peixes, principalmente os carnívoros, evoluíram de tal modo a desenvolverem estruturas acessórias ao trato gastrintestinal, para obter uma maior área de absorção, denominados cecos pilóricos, o que não foi observado em tilápia do Nilo, em nenhuma das condições estudadas. Provavelmente, isso é devido à grande área do intestino observado, o que de certo modo compensa a inexistência e/ou redução de cecos pilóricos nas espécies analisadas. 
Ferreira e outros (2013) relatam que a quantidade de cecos pilóricos é maior em peixes carnívoros e menor em espécies herbívoras e onívoras, pois essas estruturas aumentam a superfície interna do intestino, o que eleva a absorção dos nutrientes (SILVA et al., 2005).

Da mesma forma, Zimmermann e Jost (1998) relataram a inexistência de cecos pilóricos em $O$. niloticus, destacando também a grande área intestinal como forma de compensação anatômica na evolução da espécie para obter maior área de digestão e absorção dos nutrientes.

Vale ressaltar as diferenças genéticas dentro da mesma espécie, já que existem atualmente muitas variedades e linhagens que foram melhoradas ao longo do tempo, a partir das primeiras tilápias do Nilo, que também é conhecida como tilápia nilótica, introduzidas no Brasil.

Essas diferenciações observadas no presente estudo, podem também estar relacionadas diretamente a essa variabilidade genética, ao qual pode-se afirmar que as tilápias cultivadas em sistema semi-intensivo eram peixes que foram melhorados geneticamente para melhor aproveitamento dos nutrientes e maior ganho de peso. Enquanto os espécimes provindos da pesca artesanal, provavelmente, são peixes que naturalmente estão sendo selecionados no ambiente natural, principalmente com a finalidade de resistência e sobrevivência ao local.

\section{CONCLUSÃO}

As tilápias do Nilo podem apresentar modificações/adaptações do trato digestório em relação a dieta, a periodicidade de alimentação, a genética e ao meio que estão situadas. Essas adaptações podem ser facilitadas por seu hábito onívoro, caracterizado neste estudo, e que propicia retração ou expansão do intestino em cada situação. Esse trabalho fornece fortes indícios da influência quantiqualitativa do alimento inerte e natural na variação da morfologia gastrointestinal em $O$. niloticus.

\section{REFERÊNCIAS}

BANDEIRA, M.G.A., NASCIMENTO, J.S. Estudo prospectivo relativo à atividade da tilápia para a indústria de alimentos no período de 2006 a 2016. Cad. Prospec., v. 10, n. 3 p. 552-562, 2017.

BECKER, A.G. et al. Morphometric parameters comparisons of the digestive tract of four teleosts with different feeding habits. Ciência Rural, v.40, n.4, p.862-866, abr, 2010.

COSTA, D.L. Diferenças morfofisiológicas do trato gastrointestinal de tainhas Mugil liza provenientes de criação e do ambiente. 2017. 45p. Dissertação (mestrado em Aquicultura), Universidade Federal do Rio Grande, Rio Grande do Sul, 2017.

COSTA, G.M. et al. Aspectos morfológicos do estômago de Colossoma macropomum (Cuvier, 1818), tambaqui. Enciclopédia Biosfera, v.11, n.22, p. 2844, 2015.

COSTA, G.M.et al. Anatomia do tubo digestório de Leporinus fasciatus (Block, 1794), (Teleósteo, Anostomidae). Enciclopédia Biosfera, v.1, n.22, p. 2820, 2015.
DREWE, K.E. et al. Insectivore to frugivore: ontogenetic changes in gut morphology and digestive enzyme activity in the characid fish Brycon guatemalensis from Costa Rica rain forest streams.Journal of Fish Biology, v.64, n.4, p.890-902, 2004.

FAO - Food and Agriculture Organization of the United Nations. The state of world fisheries and Aquaculture: meeting the sustainable development goals. 227p. Rome, 2018.

FERREIRA, A.H.C. et al. Anatomia do aparelho digestório do tambatinga. Revista Eletrônica Nutritime, v.10, n.3, p. 2501 - 12, 2013.

GATZ JR., A.J. Ecological morphology of freshwater stream fishes. Tulane Stud. Zool. Bot., New Orleans, v.21, p. 91-124, 1979.

GNERI, F.S.; ANGELESCU, V. La nutricion de los peces iliofagos en relacion con el metabolismo general deI ambiente acuatico. Rev. Inst. Invest. Mus. Argent. Cienc. Nat. Ciencias Zoologicas, Buenos Aires, v.2 n.1, p. 1-44, 1951.

MORAES, M.F.P.G.; BARBOLA, I.F.; GUEDES, E.A.C. Alimentação e relações morfológicas com o aparelho digestivo do "curimbatá", Prochilodus lineatus (Valenciennes) (Osteichthyes, Prochilodontidae), em uma lagoa do sul do Brasil. Rev. Bras.Zool. V.14, n. 1,p. 169-180,1997.

MOREIRA, R.L. et al. Growth and gastrointestinal indices in Nile tilapia fed with different diets. Acta Scientiarum. Animal Sciences, v. 34, n. 3, p. 223-229, 2012.

SANTOS, E.L.et al. Digestibilidade aparente do farelo de coco e resíduo de goiaba pela tilápia do Nilo (Oreochromis niloticus) Revista Caatinga, vol. 22, núm. 2, pp. 175-180. 2009a.

SANTOS, E.L. et al. Digestibilidade de subprodutos da mandioca para a tilápia do Nilo. R. Bras. Ciên. Agrár. v. 4, p.358-362. 2009 b.

SILVA, N.B.; GURGEL, H.C.B.; SANTANA, M.D. Histologia do Sistema digestório de saguiru Steindachnerina notonota(Miranda Ribeiro, 1937)(Pisces, Curimatidae), do Rio Ceará Mirim, Rio Grande do Norte, Brasil. B. Inst. Pesca, v. 31, n. 1, p. 1 - 8, 2005.

SMITH, B.J.et al. Gross morphology and topography of the adult intestinal tract of the tilapian fish, Oreochromis niloticus L. Cells Tissues Organs. v.166, n.3, p.294-303, 2000

TORRES, R.G.A.; GONZÁLEZ, P.S.; PEÑA, S.E. Descripción Anatómica, Histológica y Ultraestructural de la Branquia e Hígado de Tilapia (Oreochromis niloticus). Int. J. Morphol., v.28, n. 3, p.703-712, 2010.

WILSON, J.M.; CASTRO, L.F.C. Morphological diversity of the gastrointestinal tract in fishes. Fish Physiology. The Multifunctional Gut of Fish: v. 30, p. 1-55, 2010.

ZENG, L.Q. et al. The effects of starvation on digestive tract function and structure in juvenile Southern catfish (Silurus meridionalis Chen). Comparative Biochemistry and Physiology, Part A n.162, p. 200-211, 2012.

ZIMMERMANN, S.; JOST, H.C. Recentes avanços na nutrição de peixes: a nutrição por fases em piscicultura intensiva. In: SIMPÓSIO SOBRE MANEJO E NUTRIÇÃO DE PEIXES, 2., 1998, Piracicaba. Anais... Piracicaba: Colégio Brasileiro de Nutrição Animal, 1998. p.123. 